Desalination, 83 (1991) 3-33

Elsevier Science Publishers B.V., Amsterdam

\title{
FOULING PREDICTION IN REVERSE OSMOSIS PROCESSES
}

M. BARGER and R. P. CARNAHAN

Environmental and Water Resources Engineering, University of Michigan, Ann Arbor, Michigan and Civil Engineering, University of South Florida, Tampa, Florida

\section{INTRODUCTION}

In recent years, membrane separation processes have successfully established footholds in all areas of chemical separations. Semipermeable membranes are now enhancing and even replacing long-time standard techniques such as distillation and solvent extraction (1). They are also being used in the preparation of purified chemical and biological products as well as the treatment and recovery of many industrial waste streams $(2,3)$. Many of these recent technological advances follow from successful research begun in the 1950's to desalinate seawater using synthetic membranes in reverse osmosis processes. While other methods to desalinate seawater have proven too unreliable or too expensive, the use of reverse osmosis in the production of potable water has steadily increased (4).

Despite its growing popularity and improved technology, reverse osmosis, RO, along with all membrane separation processes continues to be plagued with one persistent problem. The problem is membrane fouling (5). Eyecamp has defined this broad term as the following:

"Fouling is a condition in which a membrane undergoes plugging or coating by some element in the stream being treated, in such a way that its output or flux is reduced and in such a way that the foulant is not in 
dynamic equilibrium with the stream being ultrafiltered. In other words, something has occurred that makes the micro-environment near the membrane a nonsteady state situation." (6)

The fouling phenomenon adversely effects both the quantity and quality of the product water; the two characteristics that must be maximized for the most efficient and economical use of the process. Besides fouling there are other causes of flux decline in membrane processes such as membrane compaction and membrane hydrolysis (7). Recent evidence suggest that the chemical and physical properties of the membrane itself may be the primary controlling parameters for membrane fouling in all membrane separations ( 8 ). Unfortunately, it is difficult to isolate and identify the exact cause( $s$ ) of fouling in the closed environment of a reverse osmosis system.

This paper will present the results of experiments that outline a new method for predicting environments which facilitate the failure of an Ro membrane. The paper will initially discuss the fouling phenomenon in terms of the physical mechanisms which induce it and the current models that try to describe it.

\section{THE FOULING PHENOMENON}

There are several ways in which a Ro membranes can become fouled $(4,7,8,9,10)$. These include:

1) deposition on the membrane of colloidal particulates existing in the feedwater;

2) precipitation of slightly soluble organic or inorganic salts near the membrane surface;

3) accumulation of biological growth in the system and/or its attachment to the membrane;

4) physical or chemical reaction of some feedwater component with the membrane surface itself;

5) flocculation of organic or inorganic constituents to form large, insoluble polymers that will deposit on the membrane.

How exactly the deposited particulates restrict flow is not really known for most fouling cases. Unfortunately, the mechanism is different for different combinations of particles and membranes. It may result directly from membrane surface properties and/or from surfaces interactions of solute with the 
membrane. In addition to these interactions, membrane restrictions are also influenced by feedwater composition, chemical and physical properties of the membranes, and process operating parameters. The flow restriction may be caused by the blockage of interstitial spaces or the capillary pores in the separation layer of the membrane $(10,11)$. Alternatively, it may be the result of a fouling layer sorbed to deposited salts on the membrane surface. In any event, theoretical investigations of fouling mechanisms must include locating where the blockage actually occurs as well as determining exactly what mechanisms are involved.

Tactics to predict and control membrane fouling take one of several approaches $(10,12,13,14)$. These are:

1) pretreatment of the feedwater and/or membrane;

2) periodic membrane cleaning;

3) pilot plant evaluation of system performance; and,

4) use of predictive models.

Feedwater pretreatment is a popular and somewhat effective form of prevention in many water treatment processes. Pretreatment regimes may include $\mathrm{pH}$ adjustment and use of complexing agents to ensure ionization of slightly soluble salts and metals; filtration to remove particulates; and/or addition of disinfectants for control of microbial growth. The goal of any of these pretreatment schemes is to completely remove feedwater constituents that may potentially cause fouling. Coating or treatment of the membrane surface can also be designed to prevent or minimize fouling. Unfortunately, complete removal of undesirable chemicals is impossible on both practical and economic levels.

For RO, a pretreatment scheme is commonly designed from information obtained from chemical and physical analyses of the feedwater. Design of a pretreatment scheme to remove particulates from the feed, entails the use of one or more of the following evaluations: silt density index (SDI), turbidity, electrophoretic mobility, ultraviolet absorbance at 280 nanometers, BOD and COD. Of these, only the silting index, an empirically developed laboratory test, is generally reliable for predicting colloidal fouling (10). For the others, there is little correlation between the test results and the potential of a feedwater to foul a membrane. None of these tests really provide sufficient information about the feedwater 
and no information about the integrated hydrodynamic and transport processes.

During operation of a membrane separation process, period cleaning of the membrane can be performed when the flux declines to some inefficient value. Unfortunately, no cleaning method fully restores the original product flux and yields diminishing returns the longer the membranes are used. Cleaning methods are specific not only for the type of foulant, but also for different membrane materials and the geometric configuration in which they are used $(8,10,15)$.

The third alternative to predict and control membrane fouling for a commercial system involves preliminary work on the proposed feedwater in a pilot plant study. An optimal system is designed for the potential source water based on the chemical analysis of the feedwater as discussed above. The pilot plant, complete with its appropriately designed pretreatment scheme, is operated (preferably on site) to evaluate the compatibility of one or more types of membranes with the feedwater. The performance in terms of product water flux for the system is also documented. Pilot plant tests should be run for several thousand hours $(\simeq 6$ months $)$ to properly evaluate the performance of a membrane system. The problem with this approach is that it is both very expensive and time-consuming. Despite their cost, pilot plant operation is commonly used for predicting fouling and for designing full scale systems because this method generally provides reasonably good predictability.

Predictive models for membrane fouling have not yet proven successful for general use (15). Their unreliability is due to the uniqueness of each combination of feedwater composition, membrane type, pretreatment scheme, and hydrodynamic flow conditions. Most research in this area has been done on a case by case basis, with each particular combination of potentially fouling feedwater and Ro system being described uniquely. The transport equations most commonly used for RO are derived using "ideal" feedwaters of single-component, very soluble salts. Natural waters which serve as feeds to RO systems are inherently very complex chemical systems consisting of many soluble constituents as well as suspended colloidal chemical and biological species. mathematical description of the feedwater's-chemical composition and its dynamics must be coupled with the hydrodynamics of the flow field to accurately describe the fouling system. The rates and mechanisms of particle 
deposition, a variety of possible surface interactions should also be included.

\section{TRANSPORT MECHANISMS FOR MEMBRANE FOULING}

Unlike the theories of mass transport, modelling approaches to membrane fouling do not share any basic common principles. However, several models have been developed and are used to predict and describe membrane fouling (10, 11, 14, $15,16,17,18,19)$. Preliminary to the discussion of fouling models, it is beneficial to review the concept of concentration polarization and boundary layer theory from which it is

derived. Additionally, some exploration of possible physical mechanisms responsible for the flow restriction regardless of the fouling species will be discussed.

\section{CONCENTRATION POLARIZATION}

Concentration polarization can also be an important cause of membrane fouling. Although it is not truly a mechanism for the actual restriction of flow, the phenomenon is ultimately responsible for bringing too much solute to the membrane surface which may precipitate and cause fouling. The increased concentration of a solute (concentration polarization) next to the membrane has several undesirable effects on the reverse osmosis process. Most importantly, it may result in membrane fouling due to precipitation of slightly soluble salts. Other negative effects of the higher wall concentration include decreasing the pure water permeation rate, and increasing the salt concentration that passes through the membrane in the product stream.

The concept of concentration polarization is developed from a traditional modeling approach to Ro applying a film theory analysis to the equation of turbulent flow along a single or between two flat plates. A schematic of an idealized flow field between two parallel plates for a cross flow reverse osmosis system is shown in Figure 1. The equations (20) that have been derived to describe this system are simplified to the following for continuity, momentum and solute transport:

$$
\begin{gathered}
\partial \mathrm{u} / \partial \mathrm{x}+\partial \mathrm{v} / \partial \mathrm{y}=0 \\
\mathrm{v}(\partial \mathrm{v} / \partial \mathrm{y})=(1 / \rho)(\partial \mathrm{p} / \partial \mathrm{y})+\nu\left(\partial^{2} \mathrm{v} / \partial \mathrm{y}^{2}\right) \\
\mathrm{u}(\partial \mathrm{c} / \partial \mathrm{x})+\partial \mathrm{c} / \partial \mathrm{y}=\mathrm{D}\left(\partial^{2} \mathrm{c} / \partial \mathrm{y}^{2}\right)+\mathrm{s}_{\mathrm{c}}
\end{gathered}
$$


The assumptions of steady state and of constant fluid and membrane properties are invoked in this development. In these equations, $u$ and $v$ are the velocity components of the bulk flow in the $x$ and $y$ directions (parallel and perpendicular to the membrane surface); $c$ is the concentration of the solute; $p$ is the pressure gradient; $\rho$ is the density of the feedwater; $\nu$ is the feedwater viscosity and $S_{c}$ is the net source of solute. The boundary conditions invoked for Equation 2 are the "noslip" condition at the membrane surface $\left(u_{m}=0\right)$ and no solvent flux across the membrane $\left(v_{m}=0\right)$. The conditions to be satisfied for Equation 3 are the concentration at the inlet is constant and equal to that in the feed $\left(c(x=0, y)=c_{0}\right)$; the membrane is impermeable to solute $(\partial c / \partial y=0)$; and at the membrane, the mass balance of the solute in the boundary layer $D(\partial c / \partial y)=r v_{m}\left(c_{m}(x)\right)$, where $r$ is the rejection efficiency and $c_{m}(x)$ is the solute concentration at $x$.

One of the results of this analysis is that independent velocity and concentration distributions develop along the length of the flow channel (7). The profiles for these two distributions are shown in Figure 1. The velocity boundary layer is designated by $\delta_{\mathrm{u}}$ and the smaller concentration profile is represented by $\delta_{c}$. For the commonly assumed "no-slip" condition at the wall, the velocity increases from zero at the membrane surface to the value of the bulk stream. On the other hand, the solute concentration increases from the value of the bulk stream at the edge of the boundary to some higher value next to the membrane surface.

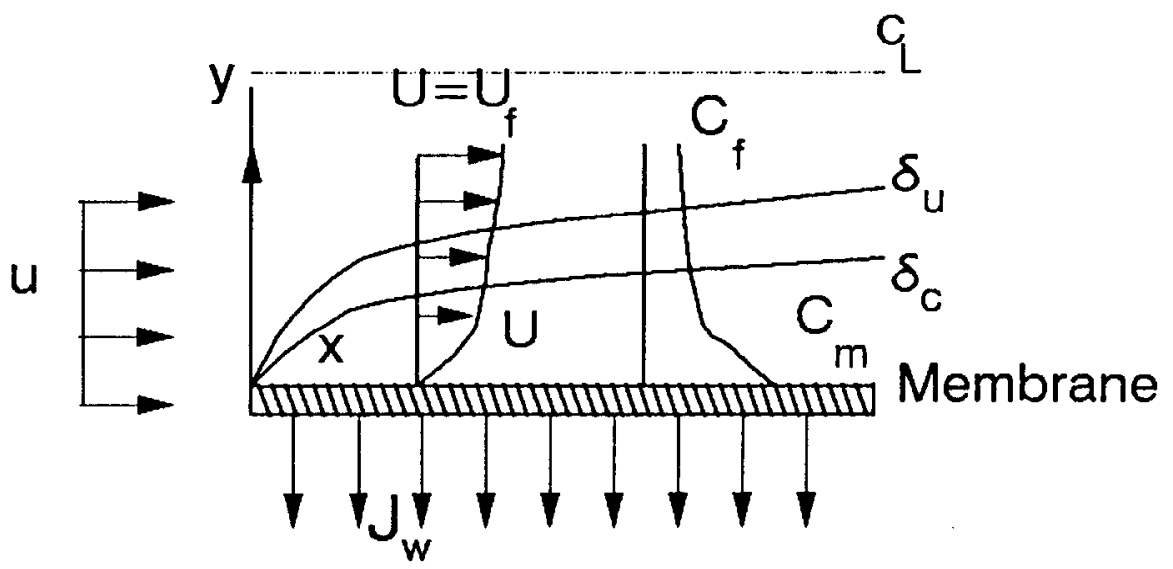

Figure 1. Idealized Flow Between Parallel Plates 

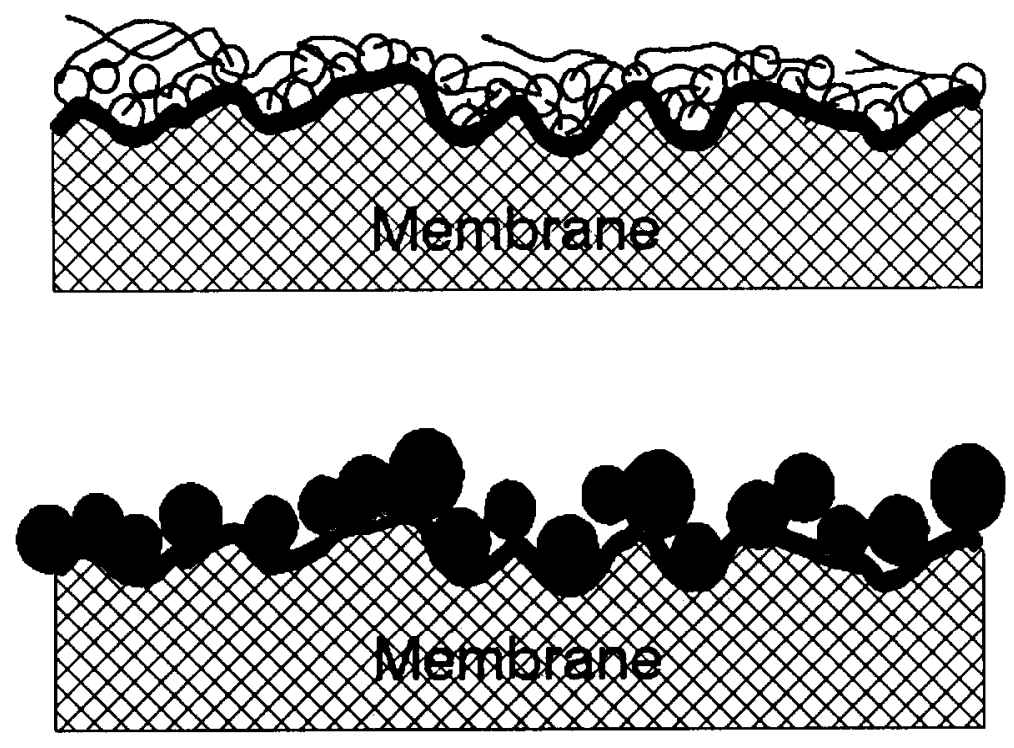

Figure 2. Flocculant (top) and Colloidal Fouling (bottom)

Solution of Equations $1-3$ requires additional information retrieved from mass transfer or other pertinent submodels (20). Application of film theory (mass transfer submodel) to the transport problem utilizes the mass balance across the boundary layer to generate a polarization factor after integration

$$
\Gamma \equiv\left(C_{m}-C_{p}\right) /\left(C_{b}-C_{p}\right)=\exp \left(J_{w} / k\right)
$$

In this equation, $\Gamma$ is the polarization factor, and $k$ is the mass transfer coefficient and equal to $\mathrm{KD} / \delta$. $\mathrm{K}$ is the partitioning coefficient of the solute between the membrane and the fluid, D is the diffusivity of the solute and $\delta$ is the thickness of the boundary layer. When the product solute concentration is assumed to be small (rejection equal to 1008), the equation simplifies to

$$
\Gamma=C_{m} / C_{b}=\exp \left(J_{w} / k\right)
$$

This equation can be used with the equations for water and solute flux (Equations 6 and 7) to determine the product flux and rejection. 


$$
\begin{gathered}
\mathrm{J}_{\mathrm{w}}=\mathrm{A}(\Delta \mathrm{P}-\Delta \pi) \\
\mathrm{J}_{\mathrm{S}}=\mathrm{k}\left(\mathrm{C}_{\mathrm{m}}-\mathrm{C}_{\mathrm{p}}\right) \\
\text { with } \left.\mathrm{A}=\left(\mathrm{D}_{\mathrm{w}} \mathrm{C}_{\mathrm{w}} \mathrm{V}_{\mathrm{w}}\right) / \mathrm{RT} \Delta \mathrm{x}\right) \text { and } \mathrm{k}=\mathrm{KD} / \delta
\end{gathered}
$$

where $A$ is the pure water permeation constant in which is defined in Equation 8a. The parameters of the mass transfer coefficient, $k$, were previously defined.

Because concentration polarization is a function of the system hydrodynamics, it can be reduced by controlling the flow. One way to reduce concentration polarization is to keep the horizontal (tangential) feed flow turbulent. Increased cross flow reduces the thickness of the laminar boundary layer, thereby increasing the relative amount of back diffusion of solute to the feed stream. The more solute that diffuses back to the bulk flow stream, the less will accumulate at the membrane (10).

Other methods to reduce concentration polarization include proper pretreatment of the feed to decrease the initial solute concentration; choosing an appropriate membrane for the particular feed; and hydrodynamic or chemical membrane cleaning. Matthiasson and Sivik (7) as well as Potts, et al. (10) have published recent reviews about membrane fouling including its relationship to concentration polarization.

\section{MECHANISMS OF FLOW RESTRICTION}

From the data accumulated from reverse osmosis experiments with ferric hydroxide at various $\mathrm{pH}^{\prime} \mathrm{s}$, Jackson and Landolt (21) hypothesized membrane fouling to be a two step process for their system. Analogous to crystallization, they observed an initial nucleation phase followed by a growth phase. Nucleation was found to be a function of the product water flux, particle size, and the number of nucleation sites. Growth was controlled by the product flux, the rate of ferric hydroxide polymerization, and the shear forces of the bulk flow. Regardless of the mechanism, growth only occurs close to the surface because of high shear forces generated by the fast cross flow of the bulk stream.

When fouling follows this nucleation-growth mechanism, $\mathrm{pH}$ becomes a significant factor in the prediction of membrane fouling by ferric hydroxide and other metals that hydrolyze. These species have their lowest fouling potential at their 
respective isoelectric points (the $\mathrm{pH}$ where the species is neutral). The colloidal particles at this point are large, discrete and coagulated. Because they are discrete entities like precipitated salts, coagulated particles settle according to Stoke's Law (settling velocity is proportional to the diameter and density of the particles). Most coagulated particles are loo large to nucleate successfully on the membrane surface. They collect on the surface, but do not flocculate, and therefore, allow for good permeate flow re because they are not closely packed. The coagulated particles were also easily removed by increasing the Reynolds number of the feedwater.

At $\mathrm{pH}$ 's away from the isoelectric point, the colloidal iron hydroxide particles are stabilized. Stabilization of any colloidal particles results in their behavior being controlled by their surface charge. The stable particles remain small and independent as they are carried to the membrane. These small particles can easily nucleate at active sites on the membrane. Ferric hydroxide particles attached to the membrane surface either by van der Waal's forces, the mechanical forces of the water flux pushing them to the membrane surface, or some other attractive force. After sufficient sites have been nucleated, growth via polymerization began. Once attached, the stable iron (or other hydrolyzable metal ion) colloid particle may form many polymeric hydroxide bridges to other similar particles. Ultimately, a flocculated solid phase builds up with some of the particles attached to the membrane. These attached flocs cause serious loss of permeate flux and permanent retention of the iron on the membrane. Figure 2 illustrates the difference between flocculated and coagulated particles at the surface of the membrane.

Although limited to hydrolyzable metals and the conditions of their experiments, Jackson and Landolt's studies are important because they focus attention on the fact membrane fouling cannot be predicted by strict mass transport models. In addition to the solute's solubility, other properties of the feedwater and membrane as well as surface forces must be considered when analyzing membrane fouling by chemical species and/or colloidal particles.

Significant research and modelling has also been carried out with colloidal fouling by unreactive particles in ultrafiltration $(22,23,24,25,26,27)$. These studies were conducted to increase the understanding of the mechanical 
transport of discrete particles in reverse osmosis flow fields, i.e., their lateral migration, and/or particle trajectories. The same authors have also investigated the mechanisms of particle interaction with the membrane surface.

\section{MODELS FOR MEMBRANE FOULING}

The basic framework of three fouling models will be reviewed. The gel polarization model was initially developed from ultrafiltration research and later applied to reverse osmosis and other membrane separations. The resistance-inseries model uses a phenomenological approach to mathematically define fouling. A transport-accumulation model extends the basic hydrodynamic flow equations to include particle transport to the membrane and growth of a solid phase at the membrane.

\section{GEL-POLARIZATION MODEL}

The basic physical model for gel-polarization begins with the transport model for flow past a flat plate. The velocity and solute concentration boundary layers develop next to the membrane surface as shown in Figure 3. However, species that form macromolecules will not only polarize next to the membrane, but polymerize and accumulate as a solid next to the membrane. Molecules that polymerize do so to a gel point, $\mathrm{C}_{\mathrm{g}}$, a constant and characteristic concentration for each polymer. At this concentration, the macromolecular fluid no longer behaves as a Newtonian fluid. The macromolecules lock the solvent water molecules into a gel network. This gel network becomes a defined layer of low permeability on top of the impermeable membrane. This gel layer will also displace from the surface any concentration boundary layer that has developed. In terms of the gel-polarization model for reverse osmosis, eventually a layer of constant concentration macromolecule is formed at the surface of the membrane. The concentration of this gel is dependent on the morphological, physical, and chemical properties of the feed solution. It does not depend on the feed concentration, the operating pressure, the properties of the membrane, or the hydrodynamic conditions in the hyperfiltration system.

Additionally, the gel layer may have an increasing thickness as more macromolecules are brought closer to the membrane. The thickness of the gel will continue to increase until a steady state condition develops across the displaced 


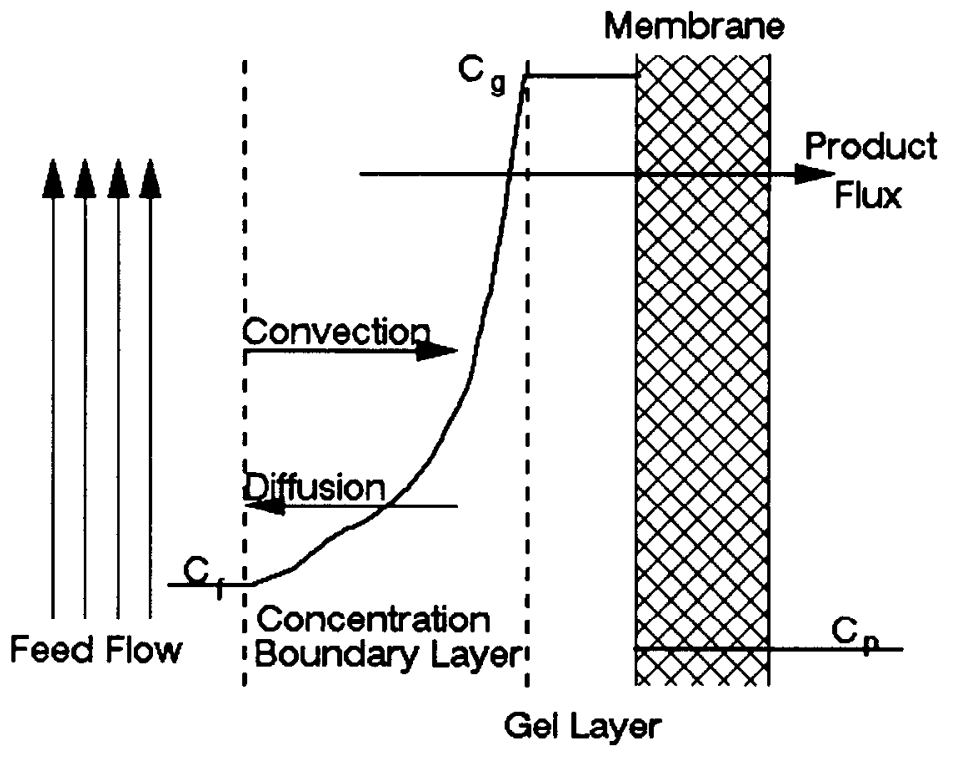

Figure 3. Schematic of Gel Polarization Model

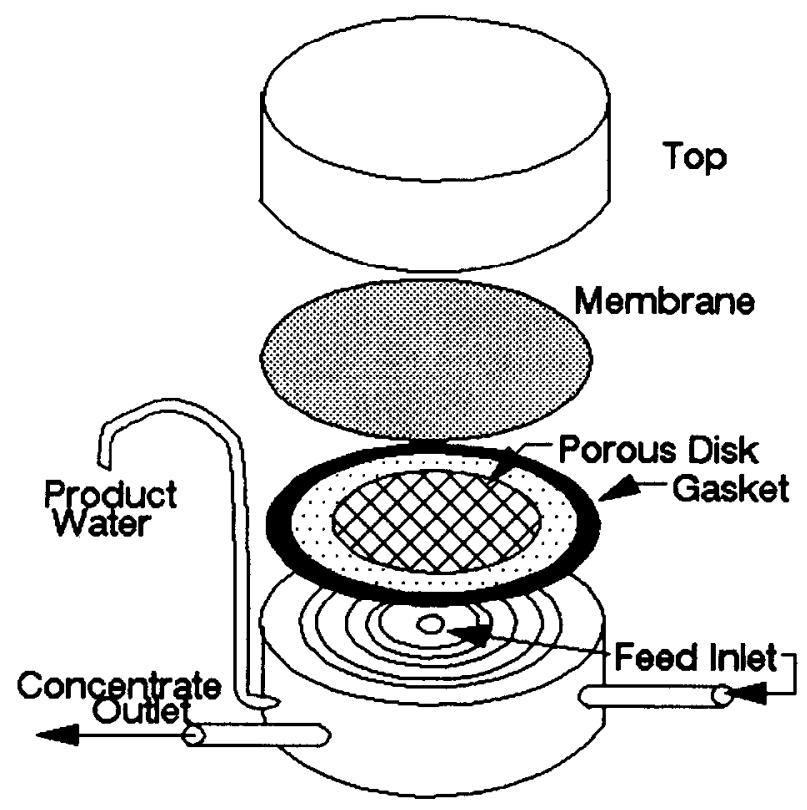

Figure 4. RO Test Cell 
boundary layer. Because this gel layer is assumed to be much more permeable than the membrane, the permeate flux, $J_{w}$, becomes dependent only on the rate of back diffusion of the solute from the gel into the bulk stream (for a constant concentration feed). Substituting the gel concentration, $C_{g}$, for the wall concentration, $C_{m}$, in the integrated form of the boundary layer mass balance, yields the following similar equation,

$$
J_{W}-(D / \delta) \ln \left(C_{g} / C_{f}\right)
$$

The concentration of solute in the product stream is assumed to be insignificant in this development.

The gel-polarization model works well for macromolecular solutions in most membrane separations. Used for particulate fouling by stabilized colloidal particles it predicts permeate flux only within two orders of magnitude $(14,28,29)$. This poor correlation of data to the gel-polarization model is believed to be related to the fluid dynamics of the colloid particles being small and discrete bodies travelling in a moving fluid. Several hydrodynamic modifications of the gelpolarization model have been developed to improve its correlation with experimental colloidal fouling data. Some of these attempts to extend the usefulness of the gel theory are reviewed by Porter (29) and Belfort and Altena (30).

\section{RES ISTANCE - IN - SERIES}

The resistance-in-series model is a phenomenological approach to fouling first developed for ultrafiltration. It has also been successfully applied to reverse osmosis by Belfort and Marx (15), Schippers, et al (31) for colloidal fouling, and by Okazaki and Kimura (32) for slightly soluble salts. The model starts with the basic flux equation for the product water, with the water flux proportional to the change in pressure. This model interprets the proportionality constant to be the system's resistance to flow of product water instead of the permeation coefficient. In most common RO transport models this constant is referred to as the pure water permeation coefficient, A, defined in Equations 6 and $8 \mathrm{a}$. Inverting the pure water permeation constant will give a value to the resistance of the membrane, $R_{m}$, to the flux of product water. For any membrane system in which fouling occurs, there will be additional flow resistances, including a resistance to 
flow from the deposited fouling layer (the cake resistance, $R_{c}$ ) and the resistance of the boundary layer concentration polarization, $R_{b 1}$. The resistances act in series to retard permeate flow. Using this model, a general equation for the pure water flux for a fouling feedwater would be

$$
\mathrm{J}_{\mathrm{w}}=\left\{1 /\left(\Sigma \mathrm{R}_{\mathrm{i}}\right)\right\}(\Delta \mathrm{P}-\Delta \pi)
$$

Membrane resistance is easily obtained experimentally from the data obtained from a membrane pure water permeation study at the desired operating pressure. Using $R_{m}, R_{c}+R_{b l}$ can be calculated from the permeation data of an experiment with the designated fouling feedwater. However, the resistance of an individual fouling layer is more difficult to predict or acquire directly. For each particular foulant $R_{c}$ will depend upon the physiochemical properties of the solution constituents and the membrane, as well as the flow field.

The resistance of the cake layer is commonly predicted using the model of flow through porous media (filtration) for colloidal feedwaters. It is calculated using the Carmen-Kozeny equation for porous media permeability $(7,26)$. However, flow through porous media or traditional filtration analysis differs greatly from the flow regime that exists in membrane processes. Belfort and Marx (15) warn of at least three important inconsistencies when this standard filtration type analysis is applied to reverse osmosis. First, filtration does not have the cross flow hydrodynamics of reverse osmosis. Secondly, the feed of the reverse osmosis experiment does not have constant suspended solid concentration. Lastly, the pressure drop across a hyperfiltration membrane is much larger than the pressure drop across a porous media or the fouling layer in reverse osmosis. Additionally, the pressure drop across the membrane increases during the process as a function of the increasing pressure gradient (due to fouling) across the membrane.

Other considerations should also be made when applying standard filtration analysis to reverse osmosis. For example, the cake layer is dynamic, i.e., its thickness constantly increases until the shear forces of the flow field restrict its growth. Therefore, any mathematical expression for cake resistance should include some dependence for the rate of growth of the fouling layer. This term may be either the rate of deposition for coagulated colloidal particles, the rate of 
flocculation for stable colloids, or the rate of growth for the crystals of slightly soluble salts. Most generally, $R_{c}$ is described in terms of the cake layer thickness as a function of time.

Kimura and Nakao (19) circumvented the traditional filtration analysis by describing the cake resistance, $R_{c}$, in terms of cake growth. The serial resistance approach was applied to colloidal feedwaters from industrial wastewaters in which $R_{c}$ was defined to be a function of the cake layer thickness. In the mass balance at the membrane, the growth of the cake layer was included in an accumulation term. Okazaki and Kimura (32) later applied this same time-dependent idea to the chemical reaction fouling by calcium sulfate, $\mathrm{CaSO}_{4}$. They described $R_{c}$ in terms of $\alpha$, a resistance factor per unit weight of the cake or scale; and $w$, the weight of the scale per unit area exposed membrane:

$$
R_{c}=\alpha w
$$

To acquire $\alpha$, a constant pressure filtration experiment was run. Using the growth rate of crystallization, the mass balance across the boundary layer, the pure water flux, and the definition of the cake resistance, a system of four equations were solved numerically for the parameters $J_{w}, R_{c}$, w and $s$. Respectively, these characteristics are the pure water flux, the cake resistance, the weight of the scale per unit area membrane, and the degree of supersaturation at the membrane.

Unfortunately, this type of analysis presumes that considerable information is known about the exact species present in a reverse osmosis feed stream, their solubility, their crystalline geometry, and their solid phase growth kinetics. Much of this information is available for simple common salts in single component systems. It is not available for the chemically complex natural feedwaters or effluent wastewater streams to be treated by reverse osmosis. The individual components of these feedwaters will affect each other's solubility, growth kinetics, and concentration polarization. These essential factors would have to be experimentally determined for each feedwater for an accurate analysis by this method.

TRANSPORT - ACCUMULATION APPROACH

Recently, Siler (33) developed a numerical solution of the 
governing field equations for a fouling system. He used a discrete time Galekin method to solve the system of equations for soluble and slightly soluble salts in both continuous flow and batch Ro systems. Siler included an accumulation term in the equation for the mass balance at the membrane surface. For slightly soluble salts, this term requires knowledge of the salt's solubility, crystallization growth parameters, adsorption characteristics, and the particle trajectory in the flow channel. Many of these are the same factors that Okazaki and Kimura used to calculate the cake resistance in the resistance-in-series analysis for slightly soluble salts.

Mathematically, Siler's analysis begins with the basic solution scheme as that for the governing transport equations of reverse osmosis. First, a velocity profile must be developed for the defined channel geometry and flow regime. This profile is then used to solve the continuity equation. The system of equations (for soluble salts) is then solved to find the membrane concentration, $C_{m}$, from which the pure water flux, $J_{w}$, and solute concentration in the product, $C_{p}$, are calculated. The same analysis for sparingly soluble salts follows the same algorithm iterating until $\mathrm{C}_{\mathrm{m}}$ is greater than the saturation concentration of the salt. At this point, solution scheme uses the mass of the particle formed to calculate its velocity and trajectory towards the membrane. Once a particle reaches the membrane, its weight is added to the mass of any existing fouling layer. The pure water flux is calculated from an updated cake resistance, and the entire scheme is checked using a new mass balance calculation. While one particle may be reaching the membrane surface, the model also allows for the simultaneous formation, growth, and transport of other particles.

This dynamic model exhibited variable success for soluble, slightly soluble, and organic solutes, as well as for colloidal suspensions when compared to experimental results. Siler's experimental data supported his model especially well for the batch process of the designated feedwaters, and for the continuous flow of the very soluble salts.

Gilron and Hasson (34) have developed a boundary layer integral model using mass transfer equations and precipitation (crystallization) kinetics for laminar flow between two flat plates. Comparison of experimental and simulated results showed that membrane concentration is relieved with the onset of precipitation. The model, however, is developed with the 
assumption that the precipitated salt layer is thin as to allow for constant permeate passage through the foulant layer. This assumption may not be applicable to most situations.

Regardless of their weaknesses, these models are some of the first one to incorporate many of the physical and chemical parameters of a potentially fouling feedwater in the governing equations of mass and momentum conservation.

\section{EXPERIMENTAL}

The reverse osmosis test cell used to develop this membrane fouling prediction method is presented in Figure 4. The feedwater is pumped with suction from a holding tank through a preliminary 0.2 micron cartridge filter and to the pressure chamber containing the separation membrane. Pressure gauges and flow meters are used to monitor a system's feed, concentrate and product lines. A needle valve on the concentrate side of the cell controls the system pressure.

The two inch diameter stainless steel Osmotic test cell was fed by a high pressure model 650-S-Pulsafeed diaphragm metering pump. An eight cubic inch nitrogen filled Cat Pump pulse dampener was pressurized to 250 psig and put in line between the pump and the test cell. The cell pressure was controlled by a needle valve on the concentrate side and monitored with a $A B M$ pressure gauge.

A UOP Fluid Systems medium pressure polyurea thin film composite (TFCM) membrane was used for these fouling experiments. These membrane sheets were initially washed with distilled water to remove a protective film and then stored in fresh distilled water at $10^{\circ} \mathrm{C}$. Each piece used in a reverse osmosis experiment was conditioned for four hours with distilled water under the operating pressure after which, the pure water permeation coefficient was determined.

A11 Ro experiments were run at room temperature $\left(22^{\circ} \mathrm{C}\right.$ $23.5^{\circ} \mathrm{C}$ ) at $450 \mathrm{psig}$. The pressure was kept constant during the experiments by using the fine control valve on the concentrate side of the test cell. The feedwater flow rate was calculated to be the sum of the concentrate flow rate and the product water flow rate. These later two rates were determined volumetrically.

The pump was primed with the given feedwater and set to an approximate feed flow rate as determined previously in a punp calibration. The valve controlling the cell pressure was 
adjusted until the gauge read 450 psig. The concentrate flow was measured immediately to check the initial pump setting. Three to six displacement measurements of five to ten millimeters each were collected for the product water flow rate as well as for its chemical analysis. The concentrate flow rate was also measured and collected for analysis at each feed rate.

A Dionex Ion Chromatograph (model 2010) was used for the analytical determination of all cations and anions in the feedwater, product and concentrate streams of each experiment. They were separated on appropriate columns, detected by solution conductance, and the signals integrated by a Spectra Physics integrator. These analyses allowed for mass balance calculations for each ion in each experiment, which information was used as a check on system performance.

\section{RESULTS}

The result of the experiments that produced the fouling prediction method will be documented from a development prospective. First, the method is introduced from a combination of resistance model concepts and concentration polarization experiment results. This discussion indicates the connection between the pure water permeability constant and increased feed flow rate. It also explores an experimentally observed relationship between permeate flux and soluble salt feedwater flow rate. A method investigation section follows. Questions about the observed relationships are explored. The report on actual fouling feed water studies is postponed to the Discussion section. At that point, the focus on predicting chemical precipitation fouling can be maintained since the key preliminary issues about the method have already been addressed.

\section{METHOD DEVELOPMENT}

The ideas of the resistance model for membrane fouling discussed earlier together with the analyzed results of the concentration polarization experiments with sodium chloride, suggest a possible alternative method for predicting membrane fouling. This predictive method would rely on the variation of the feedwater's permeation coefficient as a function of the 
feed flow rate to indicate if a membrane was in a fouling environment.

The influence of a fouling feedwater on a membrane can be appreciated by reexamining the permeate flux equation for reverse osmosis,

$$
\mathrm{J}_{\mathrm{w}}=\left\{1 /\left(\Sigma \mathrm{R}_{\mathrm{i}}\right)\right\} \Delta \mathrm{P}
$$

The first term in this equation uses the concepts of the resistance model to express all of cumulative caused of reduced water flux through a membrane as a single term. This total flux resistance, $R$, is the sum of all individual resistances, and has been applied to reverse osmosis and ultrafiltration of colloidal feedwaters with some success (23). The value of this lumped proportionality constant between the flux and the constant applied pressure, can be determined experimentally for any RO system. The permeation flux is measured at constant pressure. From this information, the proportionality constant can be calculated using Equation 11 and then be interpreted as either the total flow resistance or the system's permeability. Regardless of its interpretation, this parameter will contain the effects of all the known and unknown resistances of flow through the membrane. The membrane resistance will be a constant if the experiment is of short to moderate duration and no serious membrane degradation occurs. Membrane resistance has been noted in this research to be constant for short times (6-10 hours) when the feedwater is either pure water or a soluble salt. It can be experimentally determined when the feedwater is just pure water. Mathematically, the membrane resistance is the inverse of the pure water permeability constant, i.e., 1/A pw.

A11 feedwaters that contain a soluble salt will have permeation constants, $A^{\prime}$, and permeation fluxes, $J_{w}$, that will vary inversely with the sum of the resistances developed by the membrane and by the extent of the boundary layer. Additionally, if the feedwater's constituents have the potential to precipitate in the boundary layer, the resistance summation will include a term for the deposition layer. Normally, one of these resistances will dominate the others. However, for this resistance analysis it does not matter which phenomenon controls. For any type of feedwater, then, the total resistance to flow at a constant pressure, and at a given feed flow rate, can be measured even though the individual 
resistances cannot be independently determined or identified. Therefore, $A^{\prime}$, or $1 /\left(\Sigma R_{i}\right)$, which is a function of the permeate flux at constant pressure and is easy to determine experimentally, can be used to monitor permeation flux changes by varying the feed flow rate for most feedwaters.

In the test cell performance verification procedure in this research, the permeate flux of the sodium chloride feedwaters was measured at different flow rates. These concentration polarization experiments indicated that permeate flux increased with increasing feed flow rate. Since the increased permeate flux can be written as a function of $A^{\prime}$, values of $A^{\prime}$ can be determined for each feed flow rate used during the sodium chloride experiments. The results of these calculations indicated that, as expected, $A^{\prime}$ increased with increasing flow rate, and also that the trend may be linear. Additional experiments with sodium chloride and other soluble salt feedwaters verified the linear relationship of $\mathrm{A}^{\prime} / \mathrm{A}_{\mathrm{pw}}$ and feed flow rate. Data from these experiments is tabulated in the Appendix. To help correlate the results from particular feedwater experiments, the values of $\mathrm{A}_{\mathrm{pw}}$ were normalized by dividing each set of data by the pure water permeation coefficient of the membrane piece used with the feedwater. The linear relationship of $\mathrm{A}^{\prime} / \mathrm{A}_{\mathrm{pw}}$ and feed flow rate for the sodium chloride as well as those for one aluminum (III) nitrate and one aluminum (III) chloride feedwater are illustrated in Figure 5 . The model parameters from a linear least squares analysis, as well as the standard errors and correlation coefficients, are presented for these three experiments in the first three lines of Table 1.

In addition to eight runs with sodium chloride feedwaters several runs with other soluble salts were performed and the results analyzed by this method. The first three sodium chloride runs had somewhat lower values for the correlation coefficient. These lower correlations were attributed to a determinant error discovered in the measurement procedure. After the technique was refined, the ensuing chloride results had an average correlation coefficient greater than 0.95.

\section{METHOD INVESTIGATION}

A review of the results of the $A^{\prime}$ versus feedwater flow rate data generated several interesting questions. First, does the observed linear relationship hold if the experiments are run in reverse, i.e., from a higher to lower feed flow rates. 
Table 1. Summary of Model Parameters for $2000 \mathrm{mg} / 1$ Soluble Salts' Permeation Coefficients at 450 psig

Feed Slope Std Error Intercept Std Error Corr of Slope of Inter Coeff
$\times 10^{3}$
$\times 10^{4}$
$\times 10^{2}$

A) Increasing Flow Rates
$\mathrm{NaCl}$
1.22
1.16
0.81
$0.94 \quad .9821$

$\begin{array}{rrrrrr}\mathrm{A} 1\left(\mathrm{NO}_{3}\right)_{3} & 0.94 & 0.75 & 0.89 & 0.53 & .9816 \\ \mathrm{AlCl}_{3}^{*} & 1.50 & 2.00 & 0.87 & 1.42 & .9868 \\ \mathrm{NaCl} & 0.84 & 2.21 & 0.78 & 1.41 & .9345\end{array}$

B) Decreasing Flow Rates
$\mathrm{AlCl}_{3}{ }^{*}$
0.80
1.00
1.06
$0.81 \quad .9452$
$\mathrm{NaCl}$
0.64
0.95
0.86
$0.76 \quad .9784$

* The aluminum chloride solution had a concentration of 2322 $\mathrm{mg} / 1$.

Second, does the relationship return on the same curve if the experiment is run cyclically from low to high and back to low flow rates. Finally, if the hysteresis effect does occur, will the membrane return to its initial physical state after shutdown. Additional experiments were conducted to determine answers to these questions. 
To answer the first question, flux data from velocity variation experiments performed using dilute solutions of mixed electrolytes was collected. A low pressure thin film composite (TFCL) was used for these experiments which were run at 300 psig. Solutions of $340 \mathrm{mg} / 1$ calcium sulfate with either 293 $\mathrm{mg} / 1$ sodium chloride or $425 \mathrm{mg} / 1$ sodium nitrate were used as the feedwaters. The results (Figure 6 ) showed that the relationship of $\mathrm{A}^{\prime} / \mathrm{A}_{\mathrm{pw}}$ to the feed flow rate was still linear when the experiments were run from high to low feed flow rates. The correlation coefficient were all greater than 0.94 . Thus, the answer to the first question is yes, the linear relationship between the normalized permeation coefficient and the feed flow rate is independent of the direction of change of the feed flow rate. The answer to the second question was found to be "no", when experiments using soluble salt feedwaters were run through a cycle, from low to high and back to low flow rates. A hysteretic effect was observed and one example of these experimental results is illustrated in Figure 7. Both the increasing and decreasing portions of this graph are linear $\left(R^{2}=0.93\right)$. Regression information for both increasing (section $A$ ) and decreasing (section $B$ ) portions of two cyclic runs are given in Table 1. In all cases, the decreasing flow rate curve has a higher intercept and smaller slope than the increasing portion.

This observed hysteresis effect can be explained if the physical properties of the membrane material are considered. Reverse osmosis membranes are made of polymeric materials that are well known to deform upon initial exposure to a high pressure environment. This phenomenon was observed in one of the initial pure water experiments run to determine how long it took the TFCM membrane to reach a steady state permeation for pure water. For pure water, the permeation coefficient initially decreased and then approached its steady state value after 2-4 hours. This coefficient was also found to be independent of the operating pressure. To what extent any deformation of the membrane occurs, will depend on the exact material used, the operating pressure and the hydrodynamic flow regime of the applied process.

For soluble salt feedwaters, increasing the feed flow rate convectively brings more water closer to the membrane because the boundary layer thickness decreases. Also, the concentration polarization of the retained salt is smaller, making the osmotic pressure of the solution at the membrane 
surface smaller. The lower osmotic pressure of the salt at the membrane increases the net driving force for the water across the membrane. The result, as predicted by the permeate flux equation, is that more water is transported through the membrane at higher feed flow rates under the existing pressure. In the constant pressure cyclic flow rate experiments just discussed, the membrane's plastic polymeric network responded to the increased passage of water by physically loosening its structure to allow for the higher permeation rates. Once this increase in membrane porosity occurs, it is not expected to reverse, except, perhaps, after release of cell pressure and/or system shutdown. This fact is reflected in the recorded return curves of the cyclic experiments. The normalized permeation coefficient indicates the amount of permeate flux for a feedwater relative to the permeate flux of a pure water feed for the same piece of membrane. The ratio can be thought of as an indicator of the initial condition of the membrane before an experiment with respect to its maximum permeation. Therefore, the higher intercept of the $A^{\prime} / A_{p w}$ curve generated after the change of flow direction indicates a higher permeate flux than was observed for the curve generated by the increasing flow rate portion of this graph.

Whether or not the membrane would return to its initial physical state after shutdown, was also investigated. Pure water permeation coefficients were determined before and after all experimental runs. These values were statistically identical unless the membrane piece had been irreversibly damaged. To check the change of the water permeation during solute exposure, a replicate sodium chloride feedwater was exposed to a membrane piece after an intermediate run of pure water. The results are shown in Figure 8 . The curve of the initial sodium chloride feedwater lies below the curve generated from the second feed of the same concentration. Again, for any plot of $A^{\prime} / A_{p w}$ versus feed flow rate, higher curves represent more permeation relative to that produced by pure water on a particular membrane.

These results confirm that the membrane had been irreversible changed to allow for more permeation during the short time that it was exposed to the two sodium chloride feedwaters. The change the membrane structure could have been caused by the time of usage in the high pressure environment. However, none of the membrane pieces were used in the test cell for more than 12 hours, and this cause of permeation increase is unlikely. 


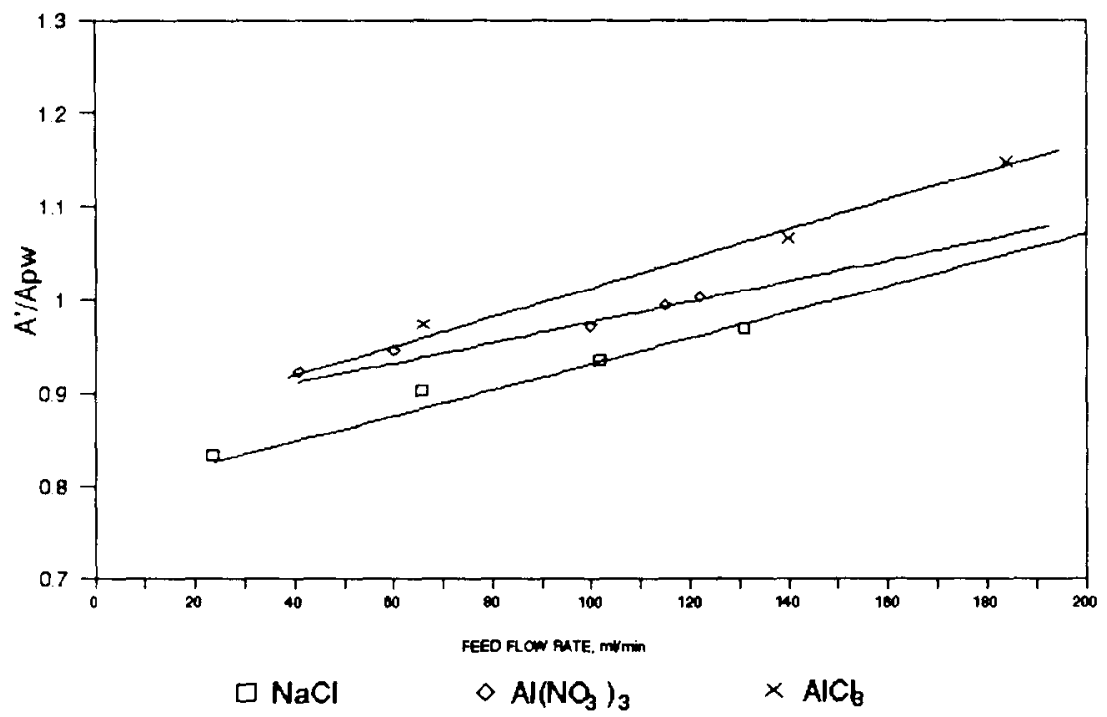

Figure 5. $\mathrm{A}^{\prime} / \mathrm{A}_{\mathrm{pw}}$ vs. Feed Flow Rate for Souble Salts at 450 psig

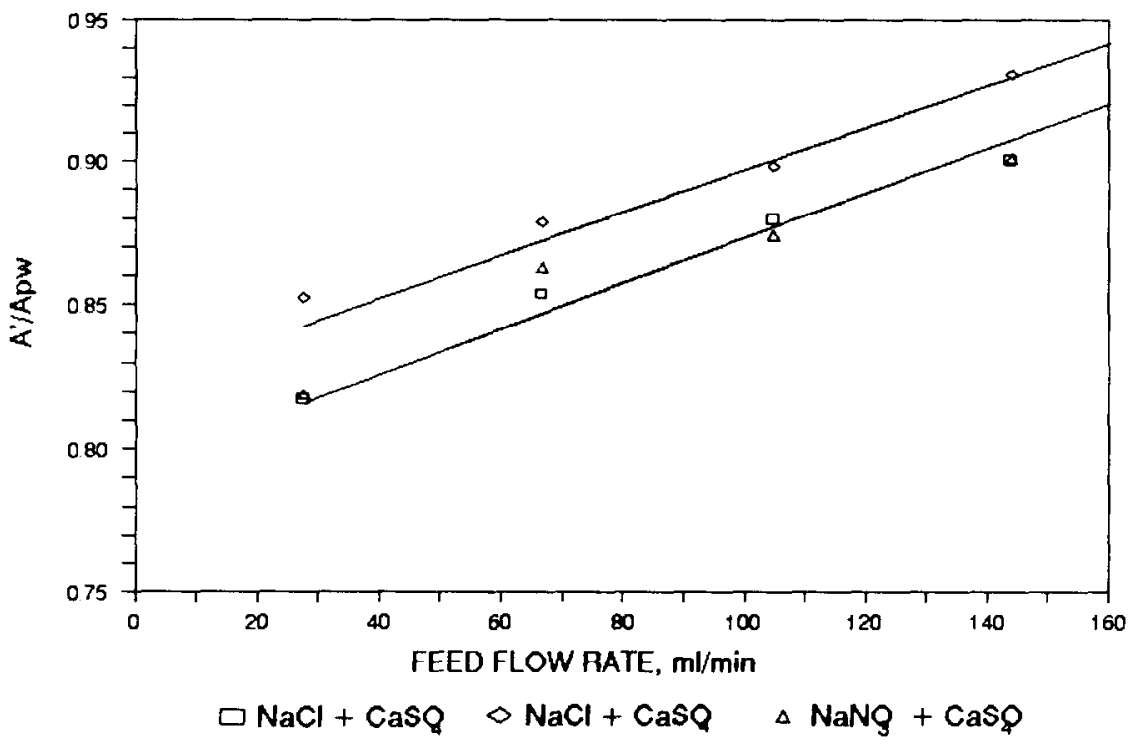

Figure 6. $A^{\prime} / A_{p w}$ vs Feed Flow Rate for Solutions of Mixed Soluble Salts using a TFCL Membrane at 300 psig 


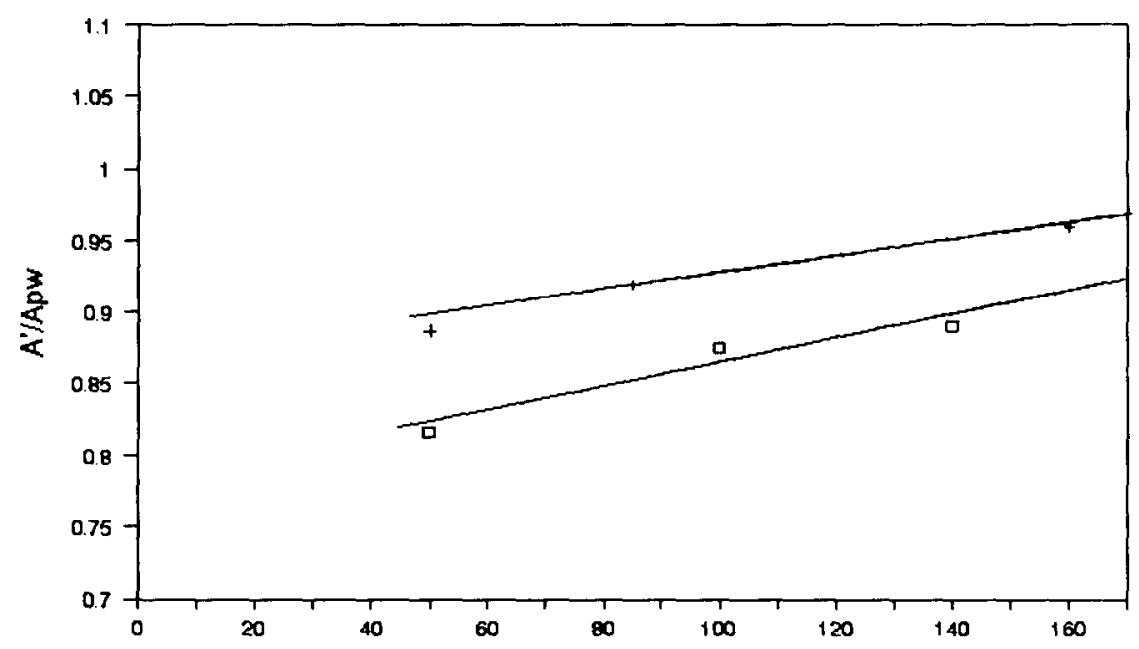

FEED FLOW RATE, $\mathrm{ml} / \mathrm{min}$

- Increasing Flow + Decreasing Flow

Figure 7. $\mathrm{A}^{\prime} / \mathrm{A}_{\mathrm{pw}}$ vs Feed FLow Rate for $2000 \mathrm{mg} / 1 \mathrm{NaC1}$ Feedwater at $450^{\circ}$ psig Showing Hysteritic Effects

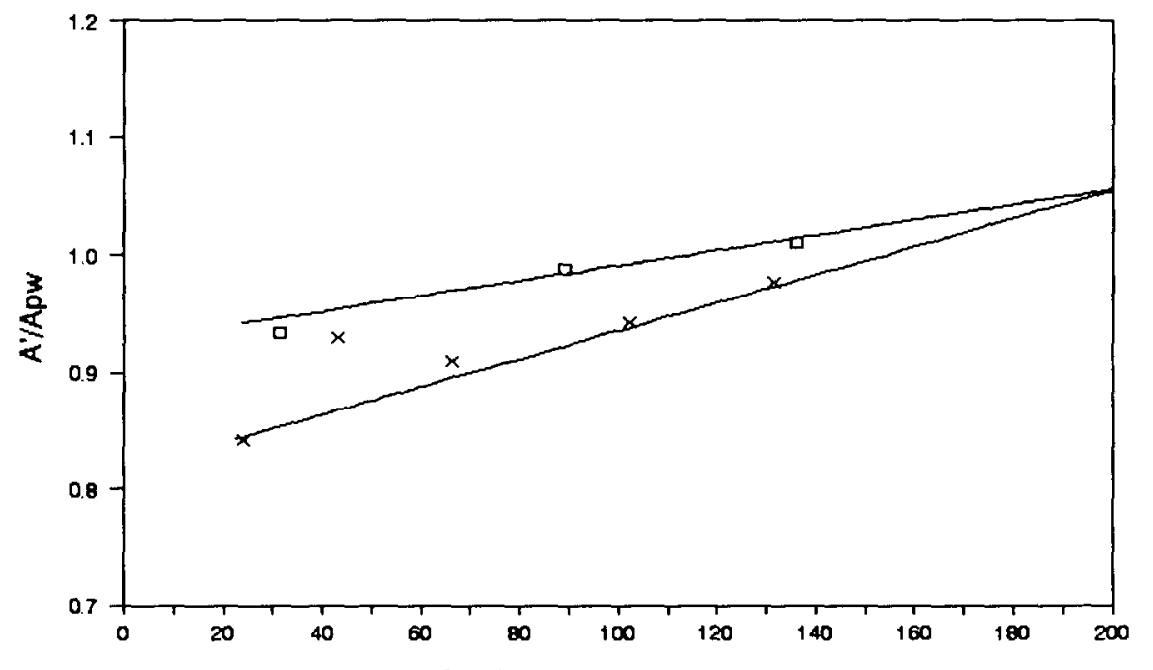

FEED FLOW RATE, ml/min

$$
\times 2000 \mathrm{ppm} \mathrm{NaCl} \text {, initial } \quad 2000 \mathrm{ppm} \mathrm{NaCl} \text {, after }
$$

Figure 8. A'/Apw vs Feed Flow Rate for Sequential $2000 \mathrm{mg} / 1$ $\mathrm{NaCl}$ Feedwaters at 450 psig with Intermediate Exposure to Pure Water 


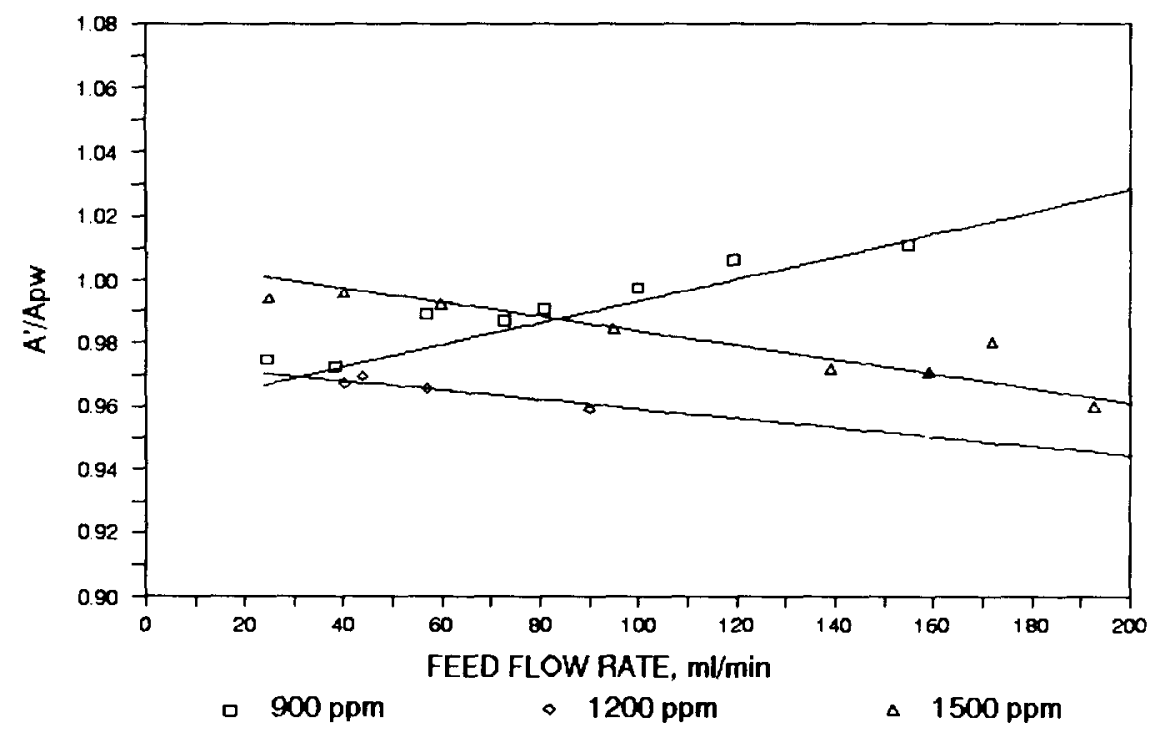

Figure 9. $\mathrm{A}^{\prime} / \mathrm{A}_{\mathrm{pw}}$ vs Feed Flow Rate for $\mathrm{CaSO}_{4}$ Feedwaters at 450 psig

\section{DISCUSSION}

Summarizing the results of the soluble salt experiments, the data showed that the proportionality constant, $A^{\prime}$, contains all of the variables that affect membrane permeation in RO processes. Also, the normalized parameter, $A^{\prime} / A_{p w}$, has been shown to increase linearly with increasing feed flow rate, due to decreasing resistance of the boundary layer. This phenomenon was also shown to demonstrate a hysteretic effect in the high pressure, turbulent flow field of reverse osmosis due to the physical properties of the membrane material itself. Most importantly, the data analysis with $\mathrm{A}^{\prime} / \mathrm{A}_{\mathrm{pw}}$ and the feed flow rate was shown to be an acceptable and reliable method for monitoring changes in the permeation flux in the reverse osmosis of soluble salts.

\section{PRECIPITATIVE FOULING}

In the present research, only chemical precipitation fouling of reverse osmosis membranes was studied. In addition to a testing protocol, it was hoped that some insight into the physical and/or chemical interactions could be gleaned from the 
experimental data. The ease of membrane replacement in the test cell and the range of control over the operating conditions should facilitate these additional studies.

Calcium sulfate solutions were chosen as the fouling feedwaters for the precipitation experiments because of their availablility, analyzability, applicability, and rejectability. Calcium sulfate is available in high purity, has a known

solubility and precipitates as a ragular crystalline solid. It is easily analyzed by several sensitive techniques, including ion chromatography, the method used in this research. It is commonly found in many natural water sources that serve as feedwaters to RO water treatment processes. The concentrations present often reach levels that make sulfate scaling a problem that must be dealt with. In reverse osmosis, it is highly rejected because of its divalent charge.

For the fouling studies, five solutions of calcium sulfate were chosen to cover a full range of saturation. These feedwaters together with their percent saturation are listed in Table 2. The activity coefficients used to determine the percent saturation were calculated using the extended DebyeHckel equation for solutions whose ionic strengths do not exceed 0.1 molar (35).

The procedure used for all of the calcium sulfate fouling experiments was identical to the procedure described previously. Three of the $A^{\prime} / A_{p w}$ vs feed flow rate results for the calcium sulfate runs are shown in Figure 9. Additionally,

Table 2. Calcium Sulfate Feedwater Concentrations and Percent Saturation

\begin{tabular}{|c|c|c|}
\hline \multicolumn{2}{|c|}{ Concentration } & Percen \\
\hline $\mathrm{mg}$ & Molar & Saturá \\
\hline & $\times 10^{2}$ & $\mathrm{x}$ \\
\hline 563 & 0.414 & 0.244 \\
\hline 836 & 0.615 & 0.452 \\
\hline 1134 & 0.834 & 0.716 \\
\hline 1139 & 0.837 & 0.720 \\
\hline 1670 & 1.230 & 1.259 \\
\hline
\end{tabular}


the regression parameters for all the fouling experiments are presented in Table 3 . Note that the two feedwaters with lower concentrations yielded curves with positive slopes. The positive slopes indicate an increase in permeation rate with increasing feed flow rate. The same results were observed for the soluble salt experiments previously described. From a macroscopic point of view, the membrane responded to these potentially-fouling solutions the same way it responded to the soluble salt feedwaters.

Table 3. Summary of Model Parameters for Calcium Sulfate Permeation Coefficients at 450 psig

\begin{tabular}{lccccc}
$\begin{array}{l}\text { Feed } \\
(\mathrm{mg} / 1)\end{array}$ & Slope & $\begin{array}{l}\text { Std Error } \\
\text { of Slope }\end{array}$ & Intercept & $\begin{array}{l}\text { Std Error } \\
\text { of Inter }\end{array}$ & $\begin{array}{c}\text { Corr } \\
\text { Coeff }\end{array}$ \\
\hline & $\times 10^{4}$ & $\times 10^{4}$ & & $\times 10^{3}$ & \\
\hline 563 & 1.12 & 0.09 & 0.94 & 0.65 & 0.9875 \\
836 & 3.05 & 0.34 & 0.97 & 3.90 & 0.9306 \\
1134 & -1.54 & 0.16 & 0.97 & 0.82 & 0.9767 \\
1139 & -2.20 & 0.23 & 0.89 & 1.82 & 0.9691 \\
1670 & -1.97 & 0.20 & 1.00 & 2.78 & 0.9616 \\
\hline
\end{tabular}

To compare the resistances in terms of the same variable, the hypothetical membrane concentrations for the calcium sulfate could be calculated. This treatment mathematically assigns all the observed flow resistance to the concentration polarization of the calcium sulfate. If precipitation and deposition does occur, these calculations will give an erroneous interpretation of the results. System mass balance calculations proved that precipitation did occur in all of the calcium sulfate experiments. 
Compared to the two lower concentration feedwaters, the results of the three remaining calcium sulfate runs show the opposite trend for $\mathrm{A}^{\prime} / \mathrm{A}_{\mathrm{pw}}$ as feed flow rate increases. These relationships are linear, like those of the lower concentration feedwaters. The negative values of the slopes indicate that the values of $\mathrm{A}^{\prime} / \mathrm{A}_{\mathrm{pw}}$, and, therefore, the permeate flux, decreased with increasing feed flow rates for the higher concentration feeds.

As indicated in Table 2, two of the fouling feedwaters had approximately the same concentration. Both yielded curves with negative slopes for $A^{\prime} / A_{p w}$ versus feed flow rate (Table 3 ), indicating that fouling had occurred. However, one curve has a much steeper slope and higher y-intercept. Since the intercept is the ratio of the fouling system's permeability to that of a system of pure water, it is clear that the $1139 \mathrm{mg} / 1$ feed offered significantly more resistance to flow than any of the other feedwaters. The initial higher resistance of this feedwater is due to the age of this particular feed, which was five days old, and may have already begun to nucleate during the waiting period. Despite being only 70 saturated, the nucleation without growth could occur in stagnant pockets of the container. On the other hand, no very large particles could have been pumped into the Ro cell because of the 0.2 micron filter upstream of the pump. All other feeds were less than 48 hours old when the experiments were initiated.

\section{SUMMARY AND RECOMMENDATIONS}

In summary, a laboratory methodology for predicting membrane fouling has been developed. This method depends on the relationship between the normalized pure water permeation coefficient ( $\mathrm{A}^{\prime} / \mathrm{A}_{\mathrm{pw}}$ ) and feed flow rate and can be run in a small test cell unit. Results of velocity variation experiments using potentially fouling feedwater are utilized to acquire this information. Further development of this method would document this relationship for other laboratory feedwaters of single and multiple components (including organics) on a variety of different membranes. Ultimately, real feedwaters would need to be used. Additionally, the expansion of this method to investigate the effects of other process variables on the change in $\mathrm{A}^{\prime} / \mathrm{A}_{\mathrm{pw}}$ as well as the exploration of the methodology in the time domain. 


\section{REFERENCES}

1. Newsfront, Chem. Eng. December, 1989.

2. MacNeil, J. C., CRC Critical Reviews in Environmental Control 18(2):91 (1988).

3. Michaels, A. S., Desal. 77:5 (1990).

4. Wood, C. F. Saline Distillation, in Handbook of Water Purification, Ellis Horwood Ltd., Chichester (1987).

5. Fane, A. G., and C. J. D. Fell, Desal. 62:117 (1987).

6. Eyecamp, W., AIChE Symposium Ser., 172, 74, 234, $(1976 / 60)$.

7. Matthiason, E. and B. Sivik, Desal. 35:59 (1980).

8. Pusch, W., Desal. 77:35 (1990).

9. Applegate, L. C., Chem. Eng. June 11, 1984.

10. Potts, D. E., R. C. Alhert, and S. S. Wang, Desal. 36:235 (1981).

11. Michaels, A. S., Chem. Eng. Prog. 64:31 (1968).

12. Van Den Berg, G. B. and C. A. Smolders, Desal. 77:101 (1990).

13. Gekas, V. and B. Hallstrm, Desal. 77:195 (1990).

14. Madsen, R. E., Hyperfiltration and U1trafiltration in Plate and Frame Systems, Elsevier Sci. Publ. (1977).

15. Belfort, G. and F. W. Altena, Desal. 47:105 (1983).

16. Hiddick, R. de Boer, and P. F. C. Noog, J. of Dairy Sci. $63: 204$ (1980).

17. Gutman, R. G., The Chem. Eng. (UK) 510 (1977).

18. Carter, J. W. and G. Hoyland, 5th Int. Symp.on Freshwater from the Sea 4:21 (1976). 
19. Kimura, S. and S. Nakao, Desal. 17:267 (1975).

20. Kleinstreuer, C., and G. Belfort, Mathematical Modelling of Fluid Flow and Solute Distribution in Pressure-Driven Membrane Processes, in Synthetic Membrane Processes (ed G. Belfort) Academic Press, Orlando, Florida (1984).

21. Jackson, J. M. and D. Lando1t, Desal. 12:361 (1973).

22. Belfort, G., and N. Nagata, Desal. 53:57 (1985).

23. Altena, F. W., G. Belfort, J. Otis, R. Riessenger, J. M. Roval, and J. Nicoletti, Desal. 47:221 (1983).

24. Trettin, D. R. and M. R. Doshi, Ind. Eng. Chem. 19:189 (1980).

25. Probstein, R. F., K. K. Cham, R. Cohn and I. Rubenstein, ACS Symposium Series No. 154, Synthetic Membranes: Vol 1. Desalinization (ed. A. F. Turback) ACS Washington DC 13 (1981).

26. Belfort, G. and B. Marx, Desal. 28:13 (1979).

27. Greene, G. and G. Belfort, Desal. 35:129 (1975).

28. Blatt, W. F., A. Dravid, A. S. Michaels and L. Ne1son, in Membrane Science and Technology (ed. J. E. Flinn) Plenum Press, New York, (1970).

29. Porter, M. C., I. E. C. Prod. Res. and Dev. 11:171 (1972)

30. Belfort, G. and F. W. Altena, Desal. 12:361 (1973).

31. Schippers, J. C., J. H. Henemaayer, C. A. Smolders, and A Kostense, Desal. 38:339 (1981).

32. Okazaki, M. and S. Kimura, J. Chem. Eng. of Japan 17:145 (1984).

33. Siler, J. L., "Reverse Osmosis Membranes, Concentration Polarization and Surface Fouling: Predictive Models and 
Experimental Verification", PhD Disseration, University of Kentucky, 1987.

34. Gilron, J. and D. Hasson, Desal. 60:9 (1986).

35. Benefield, L. D., J. F. Judkins, and B. L. Weand, Process CHemistry for Water and Wastewater Treatment, PrenticeHa11, Inc., New Jersey, (1982). 